\title{
Research misconduct agency would undermine "academic self-governance," study says
}

Previously published at www.cmaj.ca

$\mathrm{T}$ here's no need for any manner of national oversight and investigatory agency to handle research misconduct, according to a report commissioned by the Canadian Research Integrity Committee (CRIC), a loose affiliation of 16 research and academic bodies, including the three granting councils and the Association of Faculties of Medicine of Canada.

Rather, Canada should maintain the status quo and continue to rely on universities to investigate and police abuse, or, at best, establish an Office of an Ombudsperson or a Canadian Office of Research Integrity to mitigate the perception that it currently lacks a system (CMAJ 2009. DOI:10.1503/ cmaj.070213).

The upside of creating such a body is that it would throw a bone to the health sciences community, which, the report states, has expressed concerns about "a weakness in formal oversight; inadequate reporting requirements; inconsistent educational efforts; differing definitions as to what constitutes research misconduct; and poor whistleblower assistance."

But if a body is created, the report urges that its scope be limited to an educational and advisory role. Prepared by Ottawa, Ontario-based consultants Hickling Arthurs Low, The State of Research Integrity and Misconduct Policies in Canada report disdains any manner of legislated response to research misconduct, even though it concedes that the current university-based system is largely compromised as institutions are averse to "bad publicity" and fear "withdrawal of funding" in cases where their staff are proven miscreants.

CRIC organizations last month agreed to conduct separate consultations on the report amongst their respective memberships in a run-up to a meeting this winter in which they will seek to achieve a consensus on a research misconduct policy to promote to government.

In recommending the status quo, the consultants provided ammunition for the

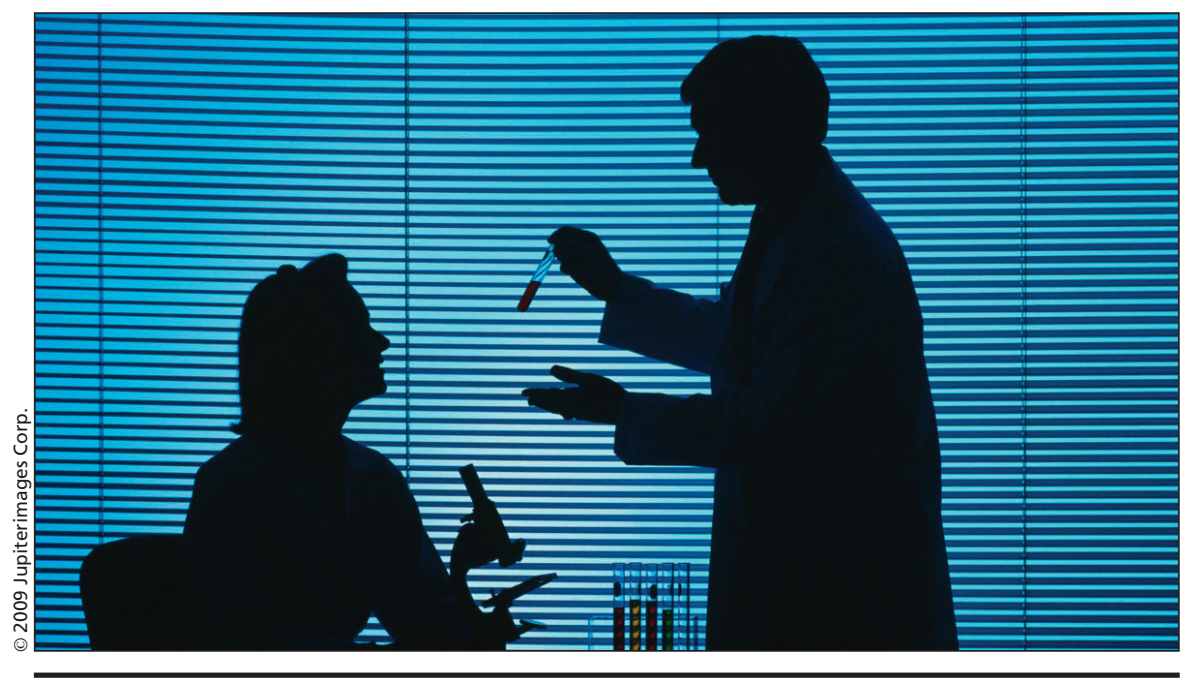

Universities have the "flexibility" to best handle the shadowy world of ghostwriting, plagiarism, falsification of data and other forms for research misconduct, states a report, The State of Research Integrity and Misconduct Policies in Canada, prepared by Ottawa, Ontario-based consultants Hickling Arthurs Low.

stance of organizations such as the Association of Universities and Colleges of Canada, which has long argued that universities should self-regulate and self-police research miscreants.

While noting that there is increased potential for conflict of interest as universities enter more partnerships with industry and chase more money from the private sector, the consulting team headed by Tijs Cruetzberg argues that the current system for handling research misconduct has the advantage of being very flexible and is in keeping with "academic self-governance."

The system is highly decentralized and entirely reliant on vagaries within individual institutions, but "is accommodating of the complexity of many misconduct allegations and allows for discretion in dealing with cases, many of which, it is noted, are based on misunderstanding or due to poor oversight," the report states.

It adds that the status quo is preferable to legislation but should nevertheless be strengthened by adopting national definitions of what constitutes research misconduct; annual public reporting requirements; and standardized guidelines for procedures to address misconduct allegations.
There is a risk to a status quo approach, though, the report concedes. The nation's three granting councils the Canadian Institutes of Health Research, the Natural Sciences and Humanities Research Council and the Social Sciences and Humanities Research Council - would continue to have no authority to police misconduct and could not address the problem of "competing obligations and interests" within universities. "While the councils are well positioned to develop policies related to research misconduct, they are not so well situated for being directly involved in specific cases, cases which can tarnish the reputations of all involved."

Canadian Association of University Teachers Executive-Director Jim Turk says maintaining the status quo will do nothing to stem the apparent tide of abuses within the health sciences, where ghostwriting appears to have become the norm (CMAJ 2009. DOI.10.1503/cmaj.109-3036) and pharmaceutical firms often distort or cloak the results of clinical trials.

There's a need for a national regime to oversee misconduct in all research, whether conducted within universities, governments or the private sector, Turk says. 
"There's some serious problems with the status quo," including a lack of consistency in how misconduct allegations are handled across the country and very little scrutiny of clinical trials funded by pharmaceutical firms, he adds.

The consultants examined data from 29 institutions and found that, on average, there are 39 misconduct cases nationally per year. But the consultants added that their estimates are probably "underreported," if only because there is no obligation on anyone to publicly report and everyone has different definitions of what constitutes misconduct.

The consultants also compared the misconduct policies of 37 institutions across Canada, interviewed 60 senior research administrators and undertook a comparative analysis of Canada's system against that of eight other nations: Australia, Denmark, France, Germany, Japan, Norway, the United Kingdom and the United States.

The "gaps" within institutional systems across Canada include limited accountability and transparency and "institutional noncompliance." There is also considerable variability as to what constitutes research misconduct; what procedures are utilized to investigate allegations; what sanctions are ultimately applied in what circumstances; and what, if any, disclosure is made to the public.

The international comparison indicated that the US, Denmark and Norway have legislated oversight systems that have clear definitions of research misconduct and a central body with investigatory powers.

Canada, Germany and the UK fell into a category of nonlegislated systems in which granting councils provide policy leadership. Germany and the UK, though, also have national arm's-length advisory bodies.

The report recommends that Canada go no further than to adopt such a body. A German-style office of an ombdusperson need not be costly, it states. "It could be limited to only one individual appointed by the Tri-Councils on a full or part time basis for a limited period of time, with assistance of secretariat support." - Wayne Kondro, CMAJ

DOI:10.1503/cmaj.109-3099

\section{More news at www.cmaj.ca}

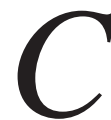
MAJ health news is now online daily as part of the journal's move to electronic publishing. The shift allows us to provide more stories to readers, on a more timely basis, while also publishing more Dispatches from the medical front. The following represents some of the pieces that have been posted at www.cmaj.ca since the last print edition of the journal.

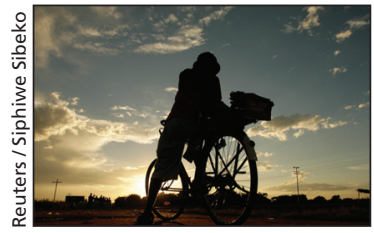

Malawi health workers grapple with rising incidence of rape: Over the past few years, health workers in Malawi have noticed an unforeseen consequence of the availability of free antiretrovirals: more rape victims are showing up in hospitals. - Wendy Glauser, Zomba, Malawi

Sodium working group to recommend voluntary reductions: Federal regulations aimed at reducing the amount of salt in prepared foods would be too cumbersome, complex and expensive to implement, according to Health Canada's Sodium Working Group. - Becky Rynor, Ottawa, Ont.

Privacy concerns raised over "secondary use" of health records: The increase in secondary use of health care data is forcing institutions to become more cognizant of privacy issues. - Ann Silversides, CMAJ

G8 nations must end "creative accounting" on foreign aid: The global financial crisis is no excuse for Western governments to renege on commitments to aid poorer nations, experts argued at an international health conference. - Roger Collier, CMAJ

Progress made in maternal and child health, but challenges remain: Among the challenges that remain in improving infant and maternal mortality rates are a lack of health care workers and delays in immunizing children in developing nations. - Roger Collier, CMAJ

Proof-of-concept projects proving productive: Short duration global health projects are becoming increasingly popular because they're a way of testing innovative ideas without much financial risk, an international health director says. - Roger Collier, CMAJ

Cost of HPV vaccine prohibitive in developing world, Nobel winner says: The death rate from cervical cancer could be significantly reduced if human papilloma virus vaccine were more affordable in the developing world, Nobel Prize winner Dr. Harald zur Hausen says. - Ann Silversides, CMAJ

\section{Dispatches}

Fees serve as deterrents to Cambodian health care: A trip to Cambodia prompts an Ontario physician to contemplate inequities in health care services. - Dina Kulik MD, Toronto, Ont.

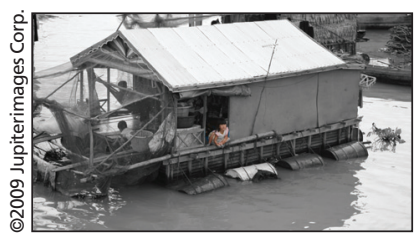

The value of context: A health sciences student contemplates the relationship between medical and cultural values. - Abi Vijenthira, Hamilton, Ont.

DOI:10.1503/cmaj.109-3095 cmaj.ca 